\title{
Managing acculturative stress and building an effective intercultural relation: A case study among international students at universiti Malaysia Sabah
}

\author{
Halina Sendera Mohd. Yakin ${ }^{1 *}$, Andreas Totu ${ }^{2}$ \\ ${ }^{1,2}$ Centre For the Promotion of Knowledge and Language Learning, Universiti Malaysia Sabah, Sabah, Malaysia
}

\section{Keywords \\ Migration \\ Sojourner \\ People Republic of China Intercultural experience Acculturative stress Cultural adaptation Universiti Malaysia Sabah}

Received: 3 October 2018 Accepted: 7 November 2018 Published: 11 December 2018

\begin{abstract}
Employing a qualitative method approach and Berry's Acculturation Theory as well as Kim's Cross-Cultural Adaptation Theory, this study investigates the intercultural experiences which focus on acculturative stress experienced and coping strategies employed by the international students in an institution of higher learning in Sabah, Malaysia, namely Universiti Malaysia Sabah, particularly among the Chinese students from the People Republic of China (PRC). It is interesting to note that even though there are many problems and hurdles in managing the teaching and learning of the PRC students, the number of PRC students enrolled in the university continues to grow yearly. The figure is outnumbered compared to other international students. Normally, the sojourners will experience a certain degree of acculturative stress or culture shock at the early phase of migration, especially among those adopting the separation and marginalization strategy of acculturation. Contrastingly, the findings reveal something different. Even though some of them have experienced a certain degree (minor) of acculturative stress, most of them could handle their migrating life as sojourners in Sabah quite comfortably. The results of this study contribute to the understanding of the obstacles and constraints faced by the sojourners and factors that lead to their successful adaptation. It offers positive implications and constructive recommendations towards building a conducive inter-cultural relation between the sojourners and the host.
\end{abstract}

(C) 2018 The Author(s). Published by TAF Publishing.

\section{INTRODUCTION}

The post-modernism world that we live in today is characterized by plurality. It indicates that diversity "is a reality of contemporary life that leads society to live in a scenario that has been dubbed as the global village, thus subsequently creates intercultural relationship. This scenario is a universal phenomenon which occurs due to several factors, namely refugees, migration, tourism, colonialism and globalisation. Migration is a phenomenon that has occurred for centuries throughout the world due to economic, social, politics as well as physical/geographical factors such as poverty, unemployment, business opportunities, location proximity, civil disputes, war, oppression and others. Thus, the contact between cultures is a centuries old phenomenon where millions of citizens have left their home country and migrated to other countries for the sake of survival by searching for a new life and/or improving their quality of lives which eventually creates coexistence between groups of citizens from different cultural backgrounds in many corners of the world.

Apart from these factors, education also contributes to the statistics of a country's population migration involving the students' transfer to another country in order to pursue study, expand knowledge, gain experience, diversify epistemological thoughts and perspectives as well as to improve quality of life and career. Based on a report by UNESCO, within the past 10 years, i.e from the years 2000 2010, the number of students who continue their studies in foreign countries has increased from 1.78 to 3.18 million (Geeraert, Demoulin, \& Demes, 2014; Harn, 2015; Siti Fatimah, Norhafizah, Noryanti, Rozieana, \& Hassan, 2015), i.e., an increase of a relatively as high as $80 \%$. As a visionary

${ }^{*}$ corresponding author: Halina Sendera Mohd. Yakin

†email: halina_sendera@yahoo.com 
and competitive country, Malaysia has also been practicing and constantly strengthening the systems and recruitment procedures of international students' which is expected to contribute a total of RM15.6 billion towards its economy by the year 2020. Similar to other states in Malaysia, Sabah has also receiving quite a big number of enrolment of international students from different countries such as the People's Republic of China, India, Algeria, Brunei Darussalam, Indonesia, Jordan, Pakistan, Somalia, Syria, Taiwan, Japan, Canada, Singapore and Turkey who are pursuing their studies at the Universiti Malaysia Sabah.

\section{Problem Statement, Objective and Significance of the Study}

This study was inspired by the glaring number of PRC students admission at UMS which consistently and relatively higher compared to other international students. Apart from that, it also centers on issues arising as a result of migration and intercultural relation among the students and Sabahan people as well as other local students in Sabah. From the economic and internationalisation point of views, this phenomenon is seen as something positive because it offers great impact and generates high commercial value to UMS particularly, and to Malaysia generally. Nevertheless, issues pertaining to socio-cultural and psycho-cultural should be given due consideration and attention as it also provides a conducive and significant impact in the long run. Therefore, documentation pertaining to intercultural experiences that focuses on international students from the PRC is significantly relevant for Universiti Malaysia Sabah and to other higher learning institution in Malaysia.

Being a minority in a society of different culture which is more dominant, immigrants and sojourners would certainly be facing problems and complications pertaining to issues such as cultural identity, cultural adaptation, aculturation and culture shock. According to the $\mathrm{U}$ and W-curve theory, the immigrants will experience culture shock based on certain temporal patent in which the duration of settlement in the new place has a significant relationship with the cultural adaptation (Baldassini \& Flaherty, 1982; Blar, Jafar, \& Monawir, 2015). Based on the previous preliminary research, in 2006-2007, the PRC students were among those who have the highest number of students facing problems in terms of both education and social aspects. The question is, after almost a decade, are the students of PRC who are pursuing their studies at UMS still facing the similar problems. In addition, other important issues that need to be highlighted are regarding the acculturative stress (culture shock) and constraints faced by the students.
Besides acculturative stress, the formation of intercultural relationship also suffers from conflict or obstacles due to prejudice, stereotype, ethnocentrism, xenosentrisme, racism, discrimination, language differences, the incompatible goals, knowledge level and so on (Baldassini \& Flaherty, 1982; Boonyarattanasoontorn, 2017; Klyukanov, 2005; Koester \& Lustig, 2012; Smith \& Khawaja, 2011; Samovar \& Porter, 2004). According to Samovar and Porter (2004), ethnocentrism has been identified as the biggest obstacle in the construction of intercultural relationship. Therefore, another matter that needs to be addressed is the obstacles that hinder the process of intercultural relationship formation among international students of PRC and the local community from Sabah and around Malaysia.

In relation to acculturative stress, the theory of crosscultural adaptation by Kim (2005) which introduced the concept of stranger (foreigners) and also the concept of host society (recipient) assumes that one of the primary keys to success in the process of cultural adaptation is motivation to learn the recipient's or the host society's culture. In this understanding, there is a need to study cultural changes experienced by students from PRC (stranger) and cultural adaptation mechanism practiced by them in order to adapt with the local community (host society).

Hence, the main objective of this paper is to examine the latest scenarios and intercultural experiences among international students, particularly from the People's Republic of China who are currently studying at Universiti Malaysia Sabah based on the intercultural communication perspective. Centered on the theory of cultural adaptation by Kim and theory of accultration by Berry as theoretical framework, this study has been undertaken to identify the types of culture shock (which is termed as acculturative stress by Berry) as well as constraints experienced by the students. Apart from that, it is also focuses on cultural adaptation and changes that occur in the process of accultration. Data collection has been carried out by utilizing the qualitative method namely participant observation, in-depth as well as focus group interviews techniques. This paper anticipates to offer positive recommendations for the future sojourners as well as the recipients societies. Indirectly, apart from contributing towards economic benefits such as in tourism, it can also helps in achieving the country's aspirations in an effort to generate social harmony and equilibrium among the communities of different cultural backgrounds at macro level through education. 
International Students at the Universiti Malaysia Sabah (UMS): Chinese Students from the People's Republic of China (PRC)

UMS is among 20 public universities in Malaysia which was established in 1994. The first intake of students was in 1995 with a total of 205 students. The number of student enrolment is steadily increasing in every academic session. Cur- rently, the total number of students in UMS is about 18,000 which comprises of both local and international students. The international students came from Brunei Darussalam, Timor-Leste, Algeria, Canada, Fiji, Greece, Indonesia, Japan, Kenya, Korea, the Philippines, the Maldives, Mynmar, Pakistan, Taiwan, Tanzania, Turkey, Vietnam and China.

TABLE 1. Statistics of international students at the Universiti Malaysia Sabah in 2014 (based on country and sex)

\begin{tabular}{|c|c|c|c|c|}
\hline \multirow[t]{3}{*}{ No } & \multirow[t]{3}{*}{ Country } & \multicolumn{2}{|l|}{ No. of Students } & \multirow[t]{3}{*}{ Total } \\
\hline & & Undergraduate & Postgraduate & \\
\hline & & $\mathbf{M}$ & $\mathbf{F}$ & \\
\hline 1 & Algeria & 0 & 2 & 2 \\
\hline 2 & Brunei & 8 & 7 & 15 \\
\hline 3 & Canada & 0 & 1 & 1 \\
\hline 4 & China & 225 & 149 & 374 \\
\hline 5 & Fiji & 1 & 1 & 2 \\
\hline 6 & Greece & 0 & 1 & 1 \\
\hline 7 & Indonesian & 3 & 2 & 5 \\
\hline 8 & Japan & 1 & 0 & 1 \\
\hline 9 & Kenya & 0 & 1 & 1 \\
\hline 10 & Korean & 2 & 1 & 3 \\
\hline 11 & Maldives & 0 & 1 & 1 \\
\hline 12 & Mynmar & 4 & 1 & 5 \\
\hline 13 & Pakistan & 0 & 1 & 1 \\
\hline 14 & Jordan & 0 & 1 & 1 \\
\hline 15 & Pakistan & 0 & 1 & 1 \\
\hline 16 & Philippines & 0 & 2 & 2 \\
\hline 17 & Taiwan & 0 & 1 & 1 \\
\hline 18 & Tanzania & 9 & 4 & 13 \\
\hline 19 & Turkish & 6 & 0 & 6 \\
\hline 20 & Vietnamese & 0 & 1 & 1 \\
\hline \multirow[t]{2}{*}{21} & East of East & & & \\
\hline & Total & 259 & 178 & 437 \\
\hline
\end{tabular}

TABLE 2. Statistics of international students at the Universiti Malaysia Sabah in 2014 (based on country and sex)

\begin{tabular}{|c|c|c|c|c|c|c|}
\hline \multirow[t]{3}{*}{ No } & \multirow[t]{3}{*}{ Country } & \multicolumn{4}{|c|}{ No. of Students } & \multirow[t]{3}{*}{ Total } \\
\hline & & \multicolumn{2}{|c|}{ Undergraduate } & \multicolumn{2}{|c|}{ Postgraduate } & \\
\hline & & $\mathbf{M}$ & $\mathbf{F}$ & $\mathbf{M}$ & $\mathbf{F}$ & \\
\hline 1 & Algeria & 1 & 0 & 2 & 1 & 4 \\
\hline 2 & Saudi Arabia & & & 1 & & 1 \\
\hline 3 & Australia & & & 1 & & 1 \\
\hline 4 & Bangladesh & & & 2 & & 2 \\
\hline 5 & Brunei & 2 & 0 & 3 & & 5 \\
\hline 6 & Canada & & & 1 & & 1 \\
\hline 7 & China & 81 & 79 & 19 & 19 & 198 \\
\hline 8 & Egypt & & & 1 & & 1 \\
\hline 9 & Germany & & & 1 & & 1 \\
\hline 10 & India & 0 & 2 & 11 & 4 & 17 \\
\hline 11 & Indonesian & 1 & 0 & 13 & 5 & 19 \\
\hline 12 & Iraq & & & 3 & & 3 \\
\hline 13 & Japan & & & 1 & 2 & 3 \\
\hline 14 & Jordan & 0 & 1 & & & 1 \\
\hline 15 & Pakistan & 0 & 1 & 5 & & 6 \\
\hline 16 & Nigeria & & & 2 & 2 & 4 \\
\hline 17 & Philippines & & & 2 & 1 & 3 \\
\hline 18 & Somalia & 1 & 0 & & & 1 \\
\hline
\end{tabular}


TABLE 2. Continue

\begin{tabular}{|c|c|c|c|c|c|c|}
\hline \multirow[t]{3}{*}{ No } & \multirow[t]{3}{*}{ Country } & \multicolumn{4}{|c|}{ No. of Students } & \multirow[t]{3}{*}{ Total } \\
\hline & & \multicolumn{2}{|c|}{ Undergraduate } & \multicolumn{2}{|c|}{ Postgraduate } & \\
\hline & & $\mathbf{M}$ & $\mathbf{F}$ & $\mathbf{M}$ & $\mathbf{F}$ & \\
\hline 19 & Syria & 1 & 0 & 1 & & 2 \\
\hline 20 & Singapore & & & 1 & & 1 \\
\hline 21 & Taiwan & 1 & 0 & & & 1 \\
\hline \multirow[t]{2}{*}{22} & Turkey & 1 & 0 & 1 & & 2 \\
\hline & Total & 89 & 83 & 71 & 34 & 277 \\
\hline
\end{tabular}

Table 2 shows that in March 2007, there were about 277 international students in UMS from 22 different countries. PRC students hold the highest number, which stood at 198. The first intake of students from the PRC was in December 2003. In January 2014, there were 437 international students in UMS and the students from the PRC have maintained the dominance in quantity with 374 students, which is roughly about $85 \%$ from the total number of intake in that year. This means, about $46 \%$ increament for the period of 8 years (2007-2015). The scenario is most likely due to the existence of an agency from Beijing, China, namely Zhong Quan Talents Service Center which was appointed (permanently) by UMS to manage and monitor the PRC students at UMS. Thus, students from the PRC have been selected as the research samples because of their dominance, in terms of number, at the UMS.

\section{LITERATURE REVIEW \\ International Student Migration Study}

The study of immigration and migration are among important areas of research in the fields of anthropology, intercultural communication, international relations and cultural sociology particularly those pertaining to the issues of cultural identity, cultural maintenance or preservation, cultural conflict and cultural changes. Various terminologies have been used by researchers as the contributing factors and outcomes of the migration and intermingling cultures such as globalisation, colonisation, modernisation, internalisation, culture shock, acculturative stress, assimilation, acculturation , adaptation, adjustment, integration, intercultural competence, intercultural effectiveness, transculturation, hybridity and indigenisation J. K. Berry (1986) Geeraert et al. (2014), Kural and Bayyurt (2016), Kealey (2015), Kim (2005), Luxon and Peelo (2009), Young and Schartner (2014), Raman, Harwood, Weis, Anderson, and Miller (2008), Zhou, Jindal-Snape, Topping, and Todman (2008).

Based on those literatures, comprehensive studies pertaining to intercultural experience among international students in Sabah are limited. However, studies focusing on intercultural communication or relation among subject or immigrant from different demographic background particularly in terms of education level and purposes of migration to Sabah had been undertaken by Samovar and Porter (2004). Meanwhile, explorative research on career experience among expatriates at public higher learning institutions in Malaysia had been implemented by Jupiter et al. (2017).

Previous studies regarding intercultural issues among students at the international level had been conducted among others by Ahmad and Weerakkody (2011), J. Berry, Kim, and Boski (1988), Baldassini and Flaherty (1982), Gao (1998), Gao and Gudykunst (1990), Gudykunst and Shapiro (1996), Gmelch (1997), Halualani, Chitgopekar, Morrison, and Dodge (2004), Jun (1984), Lin, Chen, and Song (2012), Kim (2005), Khakimova (2013), Koester and Olebe (1988) Neuliep (2012), Searle and Ward (1990), Smith and Khawaja (2011), Stier (2006), Ward and Searle (1991), Yum (1982). Those studies discussed intercultural issues such as cultural identity, cultural shock, cultural transformation, cultural adaptation, cultural adjustment, cultural preservation and acculturation which create scenarios such as assimilation, separation, integration, marginalisation as well as problems and obstacles due to cultural conflict among sojourners particularly students.

Based on temporal and historical analysis on previous studies, it shows that intercultural issues, particularly among students have gained interest in the international research arena since the middle of the 20th century up to date. This proves that such studies are still popular among researchers until today and will continue to gain attention in future because the migration scenario and intercultural issues will continue to encircle the borderless world or the globalisation era that we live in about three decades ago.

\section{METHODOLOGY}

Several qualitative methods have been applied to collect data namely participant observation as well as focus groups and in-depth interviews. The participant observation has been carried out at several locations and meeting center 
among PRC students around UMS campus in Kota Kinabalu and Labuan international campus. Data have been obtained through visual recordings in the form of pictures and videos to get the real scenarios regarding lifestyle patterns and intercultural experience among the students.

Focus groups interviews have also been implemented involving 46 PRC students from main (Kota Kinabalu) and Labuan international campus. Four interview sessions have been conducted which involved about 10-12 people per session based on purposive sampling. The interview sessions were divided into two groups, namely new students and senior students to investigate variations in terms of experience, cultural shock level, cultural adaptation and culture changes. Based on the respondents' feedbacks in the focus group interviews, 10 students were chosen to participate in the in depth interview session for them to share more informations or experiences.

\section{THE THEORITICAL AND CONCEPTUAL FRAMEWORK Berry's Acculturation Theory and Kim's Cross Cultural Adaptation Theory}

This study employed two theoretical approaches in the field of intercultural communication, namely Berry's Acculturation Theory and Kim's Cross Cultural Adaptation Theory. The combination of both theories are relevant to the research context because of the presence and synergy between the primary concepts. In addition, both theories have its own strength and very significant in the epistemological exploration and development regarding communication and intercultural relationship studies.

The Acculturation Theory was pioneered by J. W. Berry (1980) which focus on four acculturation strategies; assimilation, integration, separation and marginalization (J. W. Berry, 1980, 1990, 2005; J. K. Berry, 1986; J. W. Berry, Kim, Minde, \& Mok, 1987; J. Berry et al., 1988; J. W. Berry, Kim, Power, Young, \& Bujaki, 1989). These strategies refer to the tendency of individuals attitude in the acculturation process which can be distinguished based on two crucial aspects; 1) cultural identity preservation 2) new culture acceptance or relationship maintenance with the external/new culture (Yakin, 2003, 2007). According to Berry, acculturation is the process that involves both aspects of cultural as well as psychological changes arising from intercultural relationships among members of different cultural backgrounds.

Assimilation is the strategy used by individuals who are not so conscious about cultural identity preservation because he/she wants to be part or adapted to the new or dominant culture. On the other hand, integration is a strategy practiced by individual who want to maintain the cultural identity and at the same time try to adapt to the new culture. Separation refers to the strategy exercised by individual who want to preserve cultural identity and put distance towards individuals from the new culture. Meanwhile, marginalisations means the strategy experienced by individuals who are not able to maintain or lose his/her cultural identity and at the same time face difficulties to adapt to the new culture.

Acculturative stress is a situation in which a person or cultural group experienced a high level of cultural conflict that create problems in life or intercultural relationship, i.e problems which are not easily dealt with just by assimilating or adapting oneself into the new culture. This term can be simply understood as culture shock experienced by immigrants in the acculturation process. Berry prefers to use the word 'stress' compared to 'shock' because according to him, the concept of shock often carry a negative connotation. Compared to the concept of stress, (although typically relates to negative experience) but in the field of Health Psychology, stress can change from positive (eustress) to negative (distress). Because acculturation encompasses both positive (such as new opportunities) as well as negative aspects (such as discrimination), therefore the concept of stress is more suitable to be used to distinguish the various impacts experienced during the process of acculturation. In addition, according to Berry. the term shock does not have direct relation with cultural and psychological theories, whereas the term stress has its own place in the theoretical approach that has strongly developed over time (J. W. Berry, 2005). In this understanding, individual or cultural group who practice the marginalization strategy will suffer the highest stress while individuals who exercised the integration strategy will experience the vice-versa. Meanwhile, those who belong to the strategy of assimilation and separation are situated at the intermediate level.

The theory of Cross-cultural Adaptation developed by Young Yun Kim in 1995, i.e. a theory which was developed from her earlier theory, namely Theory of CommunicationAcculturation Kim. Eventhough there were previous studies (Kim, 2005) that tried to associate the acculturation process with communication, but none of those studies provided theoritical explanation regarding communication, especially in the process of acculturation. Therefore, Kim (2005) has pioneered the theoritical explanation regarding communication behaviour in acculturation. Kim assumed that a person's level of involvement in acculturating was dependent on the level of involvement or use of communication channels involving the local community. In this sense, 
individuals who use more local's communication channels will tend to acculturate more easily. This is because the involvement creates the complexity in individual perception towards the local which in turn facilitate their acculturation process (Yakin, 2003).

Cross-cultural Adaptation theory describes how individuals/subjects which termed by Kim as 'the stranger(s)' (i.e. individuals who immigrate to a new country including immigrants, refugees, sojourners and temporary visitors) adapt to the new culture through the communication patterns and behavior (interpersonal and mass communication) practised in everyday life. The concept of communicators in this theory involves i) the 'stranger (s)' and ii) the 'host society' (the recipients). According to Kim, one of the key features of successful adaptation is the motivation to learn a new culture.

Briefly, acculturative stress refers to the problems or constraints experienced by the PRC students, in terms of external (cultural aspects) or internal (psychological aspect) that create stress to their intercultural life and relationship. In contrast, cultural adaptation means the process of adjustment to the new cultural milieu that eventually produce comfortable feeling towards the new environment. In this study, cultural adaptation refers to the strategies or mechanisms employed by the PRC students in their efforts to adapt to the new culture, including the community and the local environment so that acculturative stress can be avoided or minimised.

\section{Acculturative Stress/Culture Shock and Changes among the PRC Students at the Universiti Malaysia Sabah}

Even though Sabah and China are both Asian countries, they have a wide difference in many aspects of socio-cultural values and settings, especially in their ways of thinking, belief, language and tradition. These cultural differences can lead to a phenomenon called acculturative stress or culture shock which brings about certain cultural changes. This study shows the PRC students at UMS have experienced acculturative stress in a certain degree especially during their early stage of migration. The acculturative stress and cultural changes experienced by the foreign Chinese students at UMS will be elucidated according to the following aspects: cultural diversity, language and communication style, foods, clothing, outfits/living pattern, and market price

\section{Cultural diversity scenario in Sabah}

One of the important aspects that contribute to the state of acculturative stress and cultural changes among the PRC students is the cultural diversity. Sabah is not only famous for its beautiful and breathtaking flora and fauna, it is also known for the diversity and the countless ethnic languages, dialects and sub-dialects. Sabah has more than 40 different ethnics and sub-ethnics. Sabah population is dominated by the Kadazandusuns, which appeared to be the largest indigenous ethnic group in Sabah, followed by the Bajaus, Malays, Muruts and other non-bumiputera groups such as the local Chinese as illustrated in Table 3 . Each ethnic group has their own distinctive ways of life, languages and dialects, norms and moral values, beliefs and religions as well as customs and traditions, which contribute to the development of their cultural identities.

TABLE 3. Statistics of sabah population 2010

\begin{tabular}{lllllll}
\hline \hline Malay & Kadazan/Dusun & Bajau & Murut & Other Bumiputras (native) & Cina & Others \\
\hline $178,0295.7 \%$ & $555,64717.9 \%$ & $436,67214 \%$ & $100,6313.3 \%$ & $640,96420.54 \%$ & $284,0499.1 \%$ & $47,0521.51 \%$ \\
\hline \hline
\end{tabular}

Source: Department of Statistics (2015)

Apart from those main ethnic groups, Sabah is also occupied by various immigrants from all over the world especially from Phillipines, Indonesia and other Asian countries. Every ethnic groups whether there are majority or minority has their own cultural uniqueness. In UMS itself, besides local Sabahan students, there are also students from peninsular Malaysia such as Kelantan, Terengganu, Perak, Perlis, Kedah, Johor, Pahang, Melaka and so on. Eventhough their mother tongues are Malay but they also have their own dialects and accents which they usually use in daily communication especially when they are mingling around with stu- dents from different states or locations.

Cultural diversity scenario in Sabah generally and UMS in particularl can be seen as one of the significant factors that contributes to the state of acculturative stress among the PRC students at the UMS because it creates confusion and difficulties to them to search for cultural cues, i.e culture to be adapted in their life especially in the earlier period of their migration. 


\section{Language aspect: Communication pattern and social re- lationship}

In UMS context, the tendency of mingling around among themselves and having less interaction with the locals create problems in cultural adaptation. From Berry's acculturation theory, this kind of attitude is characterised by the 'separation' strategy.This is mainly because of the language proficiency or competency among the PRC students. As part of the Malaysian population, Sabahans are perceived, by the PRC students, to speak standard Malaysian national language, which is the Bahasa Malaysia (Malaysian Language). However, in reality, the multi ethnicity and multi lingual Sabahans communicate in various languages among themselves apart from Bahasa Malaysia and English language. To a Sabahan, Bahasa Malaysia and English is their second and third languages. The local Chinese also speak various Chinese dialects as well such as Hokkien, Cantonese, Hakka apart from Mandarin, which they have learnt from school. The PRC students mostly speak Mandarin, which also known as Putonghua. The study found out that the PRC Chinese students encountered difficulties to communicate with the local population when they first arrived at Kota Kinabalu. They mostly relied on English language for communication because they are unable to speak in Malay or other local languages. Unfortunately, their command of English language was also not proficient which created communication and socialisation problems. Communication plays a pivotal role in human life. Inability to communicate in a foreign land due to language barriers could creates anxiety and chaos in one's life. Such anxiety and chaos have been experienced by the PRC students in Sabah.

As a way to move on with their lives, the PRC students used a lot of non-verbal communication when communicating with the locals. They were also found to mingle around with mostly Malaysian Chinese because they can speak the same language (Mandarin). Nevertheless, they still encountered difficulties communicating with the Malaysian Chinese because of differences in the way they use the language. Foreign Chinese students place more priority on tone and voice or sound and when they speak, they tend to roll their tongue. Besides that, the PRC students tend to speak quite fast and loud. Therefore, when they speak, the Malaysian Chinese could not understand them. As time goes by, they have learnt to handle their weaknesses by way of speaking slowly when they are talking with the Malaysian Chinese. The inability to communicate efficiently was also occurred due to semantic differences in certain words of Mandarin language spoken in China and Sabah/Malaysia as shown in the table below.

TABLE 4. Some examples of the differences in words (Noun) between English language, Mandarin language (China) and Mandarin language (Malaysia)

\begin{tabular}{lll}
\hline \hline English Language & Mandarin Language (China) & Mandarin Language (Malaysia/Sabah) \\
\hline Water Conditioner & Kong tiao & Lengqi \\
Refrigerator & Bing xiang & Bing chu \\
Spoon & Shao zi & Tang chi \\
Key & Yao shi & Shi Suo \\
\hline \hline
\end{tabular}

The settlement pattern is seen as another factor that contributes to these problems. The PRC students tend to live close among themselves. In the main campus (Kota Kinabalu), most of the PRC students live nearby campus. Very few PRC studends are living on-campus. Similarly, the PRC students in Labuan campus also practised the same living pattern.

\section{Academic aspect: Teaching and learning}

Due to the language problem, PRC students have also encountered teaching and learning difficulties in UMS. Previous research by Smith dan Khawaja and Stallman (2011) stated that stress and pressure in academic is absolutely higher among the international students compared to the locals because they are burdened by the pressure of second language as well as difficulty in adapting with the new academic environment. In UMS context, most lecturers that have been interviewed explained that they often encountered problem while teaching the PRC students. Apart from language problems, some of the students also have discipline, moral and concentration problems. Academic cheating or fraudulent during final examinations also often involved the PRC students such as copying, camouflaging identity to name a few. Interview with some of the respondents also verified the problems they have been facing in teaching and learning. Some of the respondents also mentioned that they do not like some of the lecturers' teaching method and behaviors. This maybe arise due to the differences in values and expectations regarding quality and service effectiveness provided by the learning institution and also perception that exist between the lecturers and stu- 
dents. The problem in teaching and learning most probably exists because of the enrolment strategy of PRC students which failed to take into consideration their English proficiency in which most of them are claimed to have unfavorable achievement or result especially in English.

\section{Practical aspects: Market price, financial and lifestyle}

China is known as the biggest world exporter or goods manufacturer because of the abundant and cheap labour force. This makes most merchandise can be purchased much cheaper in this country compared to other countries including Malaysia. All respondents stated that almost all stuffs in Sabah are more expensive compared to their own country. Moreover, China currency is lower that Malaysia, i.e $1 \mathrm{CNH}$ (Chinese Renminbi) is equivalent to $0.60 \mathrm{MYR}$ (Malaysia Ringgit). This scenario forced them to spend more money to live here and thus they needed to be thrifty or save money to survive or accommodate with daily life because most of them come here without scholarship. All of the respondents also complained that almost all stuffs and goods in Sabah are more expensive compared to China. For example, it was difficult for them to find an outfit which costs less than RM10 in Sabah but in China, they can get a shirt or pants for only RMB2 (roughly RM1). They also surprised to spot a lot of shops RM2 (RM2 shop) located in Kota Kinabalu areas which sell many ' made from China ' products. They noticed that the prices quoted are three to ten times more expensive compared to the prices in China.

Apart from that, China especially Beijing is a metropolitan city, which characterized by modernity in all aspects of life including infrastructure and facility, entertainment, skyscraper building, settlement pattern and so on. With the world highest population of about 1.4 billion (roughly $20 \%$ from the overall world population) and limited land space for accomodation, most of its inhabitants are living in skyscraper buildings such as apartments and condominiums, especially in the urban areas. In Kota Kinabalu, PRC students who live at 1 Borneo Hypermall do not experience vast differences compared to those living at terracehouse. However, this situation does not give big problem to them. Most of the respondents complained about the slow movement rate and inadequate infrastructure and facilities in Sabah compared to their modern country. Some of the respondents also complained about the hot weather in Sabah.

\section{Sociocultural aspects}

Food is another essential aspect that leads to acculturative stress and cultural changes among the PRC students. However, it can not be assumed as a dominant factor that can rise up the acculturative stress. It is just that the different taste, menu and limited food selection make them feel like far from the comfort of home. In China, they eat and use lots of noodles, dairy products, cereals, eggs, porridge and soup in their menus and daily consumption. Almost all foods are served or mixed with eggs. Meanwhile, in Sabah, they have to familiarize with the various types of foods: local traditional (such as Hinava and Bosou ), Malay, Indian and Chinese foods. Among the popular Malay foods are nasi lemak , curry and rendang. Nasi briyani , roti canai and thosai are among famous Indian foods in Kota Kinabalu.

Chinese cuisine are abandon in Kota Kinabalu, such as dim sum, chicken rice, ngau chap , kway teow noodles to name a few. Even though Chinese foods are easily available, the foreign Chinese students find them a bit different, in terms of its tastes and preparation method as compared to foods in their country. Sometimes it took for them to get use to these new foods. Eating with hands, which is common among the Malays and Indians is a total new experience for them.

For physical and grooming aspects, normally PRC students are characterised by modern, versatile and trendy. Eventhough their physical characteristics are not so much different from the local Chinese but they can be easily identified through their outfits and grooming. This scenario actually can not be seen as acculturative stress among the PRC students because they usually do not care about others' perceptions regarding their clothings styles. Occasionally, they feel uncomfortable and dissastisfied with university's dress code particularly when some of the lecturers or university staffs reprimand and forbid them from wearing inappropriate outfits.

\section{CULTURAL ADAPTATION MECHANISMS OR STRATEGIES}

There are several mechanisms or strategies practised by the PRC students and other contributing factors that facilitate them in overcoming their acculturative stress and other obstacles while studying at UMS.

\section{Verbal and Non-Verbal Communication (Kinesics) as well as Language Proficiency}

Previous discussion stated that the lack of language knowledge, whether locals or English language is one of the primary factors that create acculturative stress among the PRC students. This is due to the fact that the weaknesses in language has also trigerred other problems. To overcome this problem, the respondents have tried to learn Malay language and at the same time improved their English. They have agreed that language competency not only important in strenghtening academic achievement but also plays a vi- 
tal role in building and strenghtening their social relationship with the locals. Consequently, it also has facilitated their life at the new place. As a learning institution, UMS has also given sufficent attention in improving language proficiency not only to the international students but also the locals. To achieve this mission, UMS has offered the Intensive English Preparatory Programme which is compulsory to the international students. They also need to pass the Malay language course. Beside verbal communication, PRC students also depended much on the non-verbal aspects especially when communicating with the locals. They have also tried to socialize with the local Chinese. They usually put force or intensity in sound and tones and speak quite fast. To overcome this problem they have tried to speak slowly.

\section{Relationship with Co-Nationals and the Localstitle}

Previous studies found that quality relationship has positive correlation with high cultural adaptation and low pressure level among sojourners including international students without taking into account the source of contacts, which means the relationship built either with co-nationals or host society. The study by Geeraert et al. (2014) also found that the frequency of relationship with co-nationals correlate with high pressure level and deterioration in cultural adjustment. The study suggested that source of contacts is not really important at the beginning phase of migration but will give considerable impact in the long run. For the PRC students, the relationship developed with students from the same country or co-nationals is regarded as social support in facing the chaotic life and daily problems. In UMS, we can often see them in group whether in and around lecture venue, library, café and bus station. There were also some respondents who have made friends among the locals especially coursemates in order to facilitate their task and cooperation while handling group assignment. Those respondents claimed that the relationship frequency with local students have improved their language proficiency because they need to communicate in English and at the same time they have learnt Malay language as well. Some of the lecturers also stated that PRC students whose collaborated with locals in group assignments got better result or grade compared to those who did not.

\section{Centralised or Grouped Settlement Pattern}

In previous discussion, it was mentioned that the PRC students tend to live among themselves in a group. This kind of behavior has undermined their intercultural relationship with the locals and deteriorated their language proficiency as well. Nevertheless, looking from other dimension, the tendency have facilitated them in term of physchological aspect when encountering new environment especially during the initial phase of migration. Living far away from family and settling in a foreign country can absolutely create acculturative stress and other psychological disorder. In those situation, the PRC students felt more comfortable and safe when surrounded by their co-nationals because in a cultural coalition context, it is normal to have the tendency or desire to build relationship or search for other individuals who have similarities with oneself not only in view, habit, attitude and objective but also similar cultural background.

\section{Intermediary Individuals}

Previous studies found that the use of intermediaries is one of communication strategies practised by the Chinese to save their personal honor. This study also confirmed that the mediator services are deem important for the respondents in adapting with the new cultural milieu. The middle person was needed not only in handling social life and administration but also in other important aspects such as academic problem or teaching and learning process while studying at UMS. All respondents particularly from main campus agreed that they really need intermediary services, i.e the agency personnel who is responsible to monitor their transfer to Kota Kinabalu and Labuan. The personnel is regarded as the students' adopted mother who handle various necessity and facility particularly during their early migration including flight itineraries, accommodation, transport, activities and schedules. In addition, the respondents also claimed that they really need the service of international students' co-ordinator to help them especially in term of academic issues. The co-ordinator is needed as a reference or academic advisor regarding teaching and learning problems such as course selection and registration, credit hours increment or decrement, evaluation or examination, grades or academic as well as non-academic achievements. The co-ordinator also acts as a mediator between the students and the administrator. In this sense, the co-ordinator is regarded as an individual who supports and discusses their needs and problems to the authority or particular parties. Apart from that, the respondents also stated that the personnels from Centre of International Affairs as their savior in assisting them with issues such as student visa applications, administrative advices, orientation activities and the like. 


\section{RECOMMENDATIONS FOR TEMPORARY IMMIGRANTS' (SOJOURNERS)}

Sojourners must find ways and means to survive in the new surrounding with different socio-cultural values. Thus, in order to make their life more comfortable in this country, they have to adapt to the local or the dominant culture. Similarly, the Chinese students from the PRC, who came to Sabah, willingly or unwillingly are compelled to observe the socio-cultural values of the host country. Consequently, they have to accept and conform to Sabah culture and tradition to a certain degree. This section is reserved to propose some recommendations that can be practiced by the international students towards building an effective intercultural experience.

\section{Basic Components of Intercultural Competence}

Previous studies discovered that in order to succeed in a foreign country, the immigrants must pay attention to four key points namely knowledge, skills, ethics and motivation. The sojourners should have knowledge of their own culture, knowledge of the other culture and knowledge of intercultural communication. Communication skills are also very important including verbal, nonverbal, adaptation and empathy skills (i.e putting yourself in another person's shoes'). In this study, in order to ensure successful experiences, the international students should strive in learning the local language especially Malay while enhancing their English proficiency as a conversational language between the sojourners and the host society.Apart from that, the sojourners should also learn about ethics which has to do with moral conducts, rules and also social norms as well values embraced by the locals. In addition, they should also have motivation (i.e the act or state of being eager to do something) such as building relationship, handling anxiety, searching for knowledge and strenghtening self determination.

\section{Build Positive Relationships with the Local Community (Host Society)}

Berry's acculturation theory suggested that the immigrants or sojourners should practise integration strategy, such as try to adapt with the new culture and at the same time preserve own cultural identity. This can be accomplished by building positive relationship with the locals. Scholars have agreed that social relationship is the key element in addressing stress and cultural adaptation. A meaningful and positive relationships with individuals from different cultures will impact positively on the negative feelings that tend to arise within the intercultural scenarios such as prej- udice, streotaip, ethnosentrisme and so on. PRC students who tend to live in group among their co-nationals, should try to live together with the locals either at the same hostel, housing or residential areas. Although the clustered pattern of settlement have facilitated the international students in coping with particular situations, especially in the early stages of migration, building relationships with the locals will help their cultural adaptation in the long term, particularly in the academic advancement as well as language prificiency.

\section{Utilize Counseling Services}

When dealing with a new culture or acculturative stress, immigrants occasionally tend to move towards maladaptive strategy or overcome the situation in negative manners such as denial, self-blame, retreat, avoidance and emotional suppression. These kind of attitudes should be avoided because it could increase the level of acculturative stress. To overcome the culture shock in a positive way, it is advisable to get external assistance such as from counselling center. Universiti Malaysia Sabah provides a counselling center which is operated by the Faculty of Education and Psychology to help both local or international students who have emotional problems such as stress and depression.

In this understanding, the problem related to acculturative stress is also included in the counselling service. However, this study found that the service was not fully utilized by the international students. The findings also discovered that international students especially from the PRC were often involved with discipline problems and academic fraudulences such as cheating during examinations and camouflaging. There was also some incidents or cases involving PRC students during examination such as tried to escape from the invigilator, swallowed material evidence such as notes and cried profusely when found cheating. In this regard, this study recommends the PRC students to utilize the counseling services available which is free of charge to help them deal with not only personal problems, but also other problems relating to academic and cultural adaptation.

\section{Avoid Negative Sentiment and Improve the Perception of the Local}

As mentioned by previous scholars, there are several obstacles that hinder the process of cultural adaptation and intercultural relations namely stereotype, etnosentrisme, racism, prejudice, withdrawal and compulsion. In this sense, the sojourners particularly the PRC students should get rid of those feelings or practices because it will worsen the situation. They should avoid the negative presumption 
against the locals to facilitate intercultural relations. Some of the respondents felt that the locals were difficult to get close with and did not like to communicate with foreign students including the PRC students. Therefore the PRC students tend to be around and limit their social boundary among their co-nationals.

\section{RECOMMENDATIONS TO THE HOST SOCIETY}

This section is reserved to propose some recommendations that can be practiced by the recipient community in helping immigrants to feel comfortable in a new place and to foster harmonious environment.

\section{Support Cultural Puralism Ideology}

Cultural diversity or multiculturalism is an important social value in intercultural relation. It encourages cultural identity preservation among the minorities (J. W. Berry, 2005; Van der Noll, 2014). A society that supports multiculturalism usually provide positive services and assistances towards the immigrants. Such communities are less focused on cultural changes that prioritize assimilation, segregation and marginalization. Instead, they provide social support and sensitive to the needs of those immigrants. Recognition or respect towards other's beliefs and way of life will make the immigrants feel like they are part of the recipient community This scenario is a vital step in building harmonious relations between communities of different cultural backgrounds.

As a fast developing country which strive for stability and harmony, Malaysia also promotes cultivation of mutual understanding in its context of multiculturalism and intercultural relations that characterize the Malaysian society generally and Sabahan in particular. Unity and national integration can be created by developing intercultural communication and strenghtening social relations through bridging the knowledge gap of a particular culture. In addition, in an effort to strengthen the economic conditions, Malaysia has to continously encourge international students recruitment by restructuring certain policies and practising new procedures to facilitate the immigration process. Indirectly, it has also improved the education's quality and level of competitiveness in the country. Thus, UMS should enhance its procedure in international students enrolment by providing good service to attract students from foreign countries. In this sense, the UMS should continue supportting the ideology of harmony in diversity.

\section{Provide Intermediatary Person or Management Board}

As an effort to attract international students as well as to establish an effective intercultural relation, an institution should appoint a coordinator to monitor the international students. To realize that, a management board is needed as a mediator between a university and international students. It is recommended that the university appoint or recruit staffs who are fluent in English and also other foreign languages based on the student's population. As in UMS case for example, it should recruit more staffs who can converse in Mandarin as PRC students represent more than $80 \%$ of the overall international students population. This can facilitate communication because most PRC students in UMS do not have a good command of English. In addition, if there is enough budget, the university can also consider appointing a special co-ordinator to specifically monitor and manage the PRC students.

\section{Provide Special Counseling to International Students}

Based on interview and participant observation, it showed that the quantity of students with problems were high among PRC students compared to other international students from other countries. Ironically, the findings also showed that PRC students were among those who rarely use the counseling service provided by the University. It is widely known that counselling is a place where clients or students can express their feelings and the counselor will provide advice or guidance that can overcome or at least reduce the emotional burden. For the counselling session to be successful, language fluency is a must because it is difficult to communicate and understand one's problems if we don't understand what are being expressed. Most probably, this is the scenario that cause PRC students rarely meet the counsellors. Therefore, an institution (in this case UMS) should find a way to provide a special counselling center which is conducted or monitered by staffs or counsellors who are able to converse in foreign languages for the benefit of international students especially the PRC students.

\section{Provide Prepatory Courses and Activities Pertaining to the Local Culture}

The PRC students must take Intensive English Programme (IEPP) and pass their Malay language course. In addition, UMS can also provide extra courses pertaining to local culture including introduction to Malaysian culture including Sabahan culture. Apart from formal classroom learning, an institution can also provide a variety of extra activities related to the local culture that can be freely available to international students such as expo or cultural demonstration (cuisine, clothing, music and local artefacts), singing and dancing competitions of Malaysian and Sabahan songs and dances (such as Joget, Zapin, Sumazau, Limbai, Sumayau, 
Magunatip, Daling-Daling, Adai-Adai and Igal-Igal), local or traditional sports and games (such as congkak, wau, top, batu seremban, hand wrestling, sepak manggis, blow pipe, catapult rice pounding and giant sandals), public speaking or speech in the local ethnic languages (such as Kadazan, Dusun, Bajau, Murut and Brunei) as well as visit to cultural centers such as State Museum and Monsopiad Cultural Village. Such courses and activities do not only help international students to learn more about local cultures but at the same time appreciate the cultural heritage of the host country. Apart from expanding their knowledge horizon, it will also enhancing or developing their social relations because they can work or cooperate with local students, lecturers, staffs and communities before and during the activities. Such endeavors it can reduce the students' anxiety and uncertainty as well as acculturative stress especially in the beginning of their migration.

\section{Provide a One Stop Center for International Students}

Currently UMS has established the Centre for International Affairs to manage and monitor almost all aspects pertaining to international students. The existence of this center is relevant and should be continued because of the increasing number of foreign students to the country as a result of some modifications in government policies related to the international students' enrolment. Thus, the quality and function of the center should be strengthened, improved and diversified to accommodate the students' needs and welfare. The center should build up good cooperation and network with the ministry of higher education, immigration, foreign agencies and other relevant institutions. It is also proposed that the center is equipped with sufficent space to conduct counselling sessions, academic affairs (eg course registration) with good financial and banking facilities as well as services (such as foreign exchange and ATM machine), im- migration services (to do passport, visa and airline tickets), students' activities and so on. The center should also has direct network or link with all faculties and centres within the institution.

\section{CONCLUSION}

This study has examined the intercultural experience among the foreign Chinese (PRC) students who were and still studying at the Universiti Malaysia Sabah. It was undertaken with the objective of discovering and highlighting the acculturative stress as well as cultural adaptation mechanism among the students. This study focuses on how the PRC students cope and adapt themselves with regards to the acculturative stress phenomenon and cultural changes that occur as a result of the acculturation process. The study also offers some recommendations to deal with the cultural stress and adaptation for both the foreign students (strangers) and the respective institution as well as local students and communities (host society). It is hoped that the outcomes of this study will provide some guidances to the international students who have the intention to further their studies in Malaysia, particularly in Sabah. From a theoritical point of view, suffice to say, integration strategy is the most effective strategy in inter-cultural relation due to its significant impact in acculturative stress reduction and thus facilitate the sojourners migrating experience. The PRC students need to strive to adapt with the new culture by building intercultural relation with the locals by learning the local languages apart from improving their English. In a nutshell, language competency plays a central role in facilitating the process of adaptation and acculturation among the international students particularly the PRC students. Nevertheless, other factors as discussed in this paper are also equally important.

\section{REFERENCES}

Ahmad, J., \& Weerakkody, N. (2011). Intercultural communication, competence, teaching and learning: An analysis. Jurnal Pendidikan Malaysia/ Malaysian Journal of Education, 36(1), 45-53.

Baldassini, J. G., \& Flaherty, V. F. (1982). Acculturation process of colombian immigrants into the American culture in bergen county, New Jersey. International Journal of Intercultural Relations, 6(2), 127-135. doi:https://doi.org/10.1016/ 0147-1767(82)90043-8

Berry, J., Kim, U., \& Boski, P. (1988). Psychological acculturation of immigrants cross-cultural adaptation: Current approaches (pp. 62-89). Thousand Oaks, CA: Sage Publications, Inc.

Berry, J. K. (1986). Learning computer-assisted map analysis. Journal of Forestry, 84(10), 39-43.

Berry, J. W. (1980). Acculturation as varieties of adaptation. In Padilla, A.M (ed)., Acculturation: theory, models and some new findings. Colorado, CO: West View.

Berry, J. W. (1990). Psychology of acculturation: Understanding individuals between cultures. In. Brislin, R.W (Ed.,) Applied cross-cultural psychology. Newbury Park, CA: Sage Publications. 
Berry, J. W. (2005). Acculturation: Living successfully in two cultures. International Journal of Intercultural Relations, 29(6), 697-712.

Berry, J. W., Kim, U., Minde, T., \& Mok, D. (1987). Comparative studies of acculturative stress. International Migration Review, 21(3), 491-511. doi:https://doi.org/10.2307/2546607

Berry, J. W., Kim, U., Power, S., Young, M., \& Bujaki, M. (1989). Acculturation attitudes in plural societies. Applied Psychology, 38(2), 185-206. doi:https://doi.org/10.1111/j.1464-0597.1989.tb01208.x

Blar, N., Jafar, F. A., \& Monawir, R. P. H. R. (2015). Comparison of students' feedback between the application of a robot teacher and human. Journal of Advances in Humanities and Social Sciences, 1(1), 42-52. doi:https://doi.org/10.20474/ jahss1.1.5

Boonyarattanasoontorn, P. (2017). An investigation of thai students' english language writing difficulties and their use of writing strategies. Journal of Advanced Research in Social Sciences and Humanities, 2(2), 111-118. doi:https://doi.org/ 10.26500/jarssh-02-2017-0205

Department of Statistics. (2015). Yearbook of statistics Sabah. Retrieved from https://urlzs.com/C7r6W (Accessed on 15 July, 2017)

Gao, G. (1998). "don't take my word for it."understanding Chinese speaking practices. International Journal of Intercultural Relations, 22(2), 163-186. doi:https://doi.org/10.1016/s0147-1767(98)00003-0

Gao, G., \& Gudykunst, W. B. (1990). Uncertainty, anxiety, and adaptation. International Journal of Intercultural Relations, 14(3), 301-317. doi:https://doi.org/10.1016/0147-1767(90)90017-q

Geeraert, N., Demoulin, S., \& Demes, K. A. (2014). Choose your (international) contacts wisely: A multilevel analysis on the impact of intergroup contact while living abroad. International Journal of Intercultural Relations, 38, 86-96. doi: https://doi.org/10.1016/j.ijintrel.2013.08.001

Gmelch, G. (1997). Crossing cultures: Student travel and personal development. International Journal of Intercultural Relations, 21(4), 475-490. doi:https://doi.org/10.1016/s0147-1767(97)00021-7

Gudykunst, W. B., \& Shapiro, R. B. (1996). Communication in everyday interpersonal and intergroup encounters. International Journal of Intercultural Relations, 20(1), 19-45. doi:https://doi.org/10.1016/0147-1767(96)00037-5

Halualani, R. T., Chitgopekar, A. S., Morrison, J. H. T. A., \& Dodge, P. S.-W. (2004). Diverse in name only? Intercultural interaction at a multicultural university. Journal of Communication, 54(2), 270-286. doi:https://doi.org/10.1111/j.1460-2466 .2004.tb02628.x

Harn, P. (2015). The exploratory study on the relationships among Taiwanese college students construallevel, gratitude and intimate attachment. International Journal of Humanities, Arts and Social Sciences, 1(1), 1-5. doi:https://doi.org/ 10.20469/ijhss.20001

Jun, S.-H. (1984). Communication patterns among young korean immigrants. International Journal of Intercultural Relations, 8(4), 373-389. doi:https://doi.org/10.1016/0147-1767(84)90016-6

Jupiter, H., Othman, I. W., Suki, N. M., Yusoff, M. S., Awang, H., \& Razak, R. A. (2017). Factors influencing international student's decision in choosing study destination abroad. Labuan e-Journal of Muamalat and Society, 5(8), 40-45.

Kealey, D. J. (2015). Some strengths and weaknesses of 25 years of research on intercultural communication competence: Personal reflections. International Journal of Intercultural Relations, 48, 14-16. doi:https://doi.org/10.1016/j.ijintrel .2015 .03 .005

Khakimova, L. (2013). An exploratory study of the meaning of public diplomacy: Network approach (Unpublished doctoral Dissertation). University of Maryland, Maryland, MD.

Khawaja, N. G., \& Stallman, H. M. (2011). Understanding the coping strategies of international students: A qualitative approach. Journal of Psychologists and Counsellors in Schools, 21(2), 203-224. doi:https://doi.org/10.1375/ajgc.21.2 .203

Kim, Y. Y. (2005). Inquiry in intercultural and development communication. Journal of Communication, 55(3), 554-577. doi:https://doi.org/10.1093/joc/55.3.554

Klyukanov, I. (2005). Principles of intercultural communication. New York, NY: Pearson College Division.

Koester, J., \& Lustig, M. (2012). Intercultural competence: Interpersonal communication across cultures. New York, NY: Pearson Prentice Hall. 
Koester, J., \& Olebe, M. (1988). The behavioral assessment scale for intercultural communication effectiveness. International Journal of Intercultural Relations, 12(3), 233-246. doi:https://doi.org/10.1016/0147-1767(88)90017-x

Kural, F., \& Bayyurt, Y. (2016). The implementation of an intercultural competence syllabus to prepare study-abroad students for global communication. Educational Studies, 42(4), 378-393. doi:https://doi.org/10.1080/03055698.2016 .1195720

Lin, Y.-c., Chen, A. S.-y., \& Song, Y.-c. (2012). Does your intelligence help to survive in a foreign jungle? The effects of cultural intelligence and emotional intelligence on cross-cultural adjustment. International Journal of Intercultural Relations, 36(4), 541-552. doi:https://doi.org/10.1016/j.ijintrel.2012.03.001

Luxon, T., \& Peelo, M. (2009). Internationalisation: Its implications for curriculum design and course development in UK higher education. Innovations in Education and Teaching International, 46(1), 51-60.

Neuliep, J. W. (2012). The relationship among intercultural communication apprehension, ethnocentrism, uncertainty reduction, and communication satisfaction during initial intercultural interaction: An extension of anxiety and uncertainty management (aum) theory. Journal of Intercultural Communication Research, 41(1), 1-16. doi:https://doi.org/ 10.1080/17475759.2011.623239

Raman, P., Harwood, J., Weis, D., Anderson, J. L., \& Miller, G. (2008). Portrayals of older adults in US and indian magazine advertisements: A cross-cultural comparison. The Howard Journal of Communications, 19(3), 221-240. doi:https:// doi.org/10.1080/10646170802218214

Samovar, L. A., \& Porter, R. E. (2004). Communication between cultures. Belmont, CA: Thomson Learning.

Searle, W., \& Ward, C. (1990). The prediction of psychological and sociocultural adjustment during cross-cultural transitions. International Journal of Intercultural Relations, 14(4), 449-464. doi:https://doi.org/10.1016/0147-1767(90)90030 $-\mathrm{z}$

Siti Fatimah, A. Z., Norhafizah, M. S., Noryanti, M., Rozieana, K., \& Hassan, R. G. (2015). A study of students' performance in calculus and their attitudes toward the course using tripartite model. International Journal of Humanities, Arts and Social Sciences, 1(1), 30-35. doi:https://doi.org/10.20469/ijhss.20005

Smith, R. A., \& Khawaja, N. G. (2011). A review of the acculturation experiences of international students. International Journal of Intercultural Relations, 35(6), 699-713. doi:https://doi.org/10.1016/j.ijintrel.2011.08.004

Stier, J. (2006). Internalisation, intercultural communication and intercultural competenc2e. Journal of Intercultural Communication, 11(5), 45-56.

Van der Noll, J. (2014). Religious toleration of muslims in the german public sphere. International Journal of Intercultural Relations, 38, 60-74. doi:https://doi.org/10.1016/j.ijintrel.2013.01.001

Ward, C., \& Searle, W. (1991). The impact of value discrepancies and cultural identity on psychological and sociocultural adjustment of sojourners. International Journal of Intercultural Relations, 15(2), 209-224. doi:https://doi.org/10 $.1016 / 0147-1767(91) 90030-\mathrm{k}$

Yakin, H. S. M. (2003). Akulturasi imigran filipina: Generasi pertama dan kedua di sabah. Sabah, Malaysia: Universiti Malaysia Sabah.

Yakin, H. S. M. (2007). Identiti budaya etnik palau'di semporna, sabah: Konservasi, adaptasi dan transformasi budaya. Occasional Paper, 5(7), 34-56.

Young, T. J., \& Schartner, A. (2014). The effects of cross-cultural communication education on international students' adjustment and adaptation. Journal of Multilingual and Multicultural Development, 35(6), 547-562. doi:https://doi.org/ 10.1080/01434632.2014.884099

Yum, J. O. (1982). Communication diversity and information acquisition among korean immigrants in Hawaii. Human Communication Research, 8(2), 154-169. doi:https://doi.org/10.1111/j.1468-2958.1982.tb00662.x

Zhou, Y., Jindal-Snape, D., Topping, K., \& Todman, J. (2008). Theoretical models of culture shock and adaptation in international students in higher education. Studies in Higher Education, 33(1), 63-75. doi:https://doi.org/10.1080/ 03075070701794833 